\title{
Determining the Antimicrobial Actions of Tea Tree Oil
}

\author{
Sean D. Cox ${ }^{1}$, Cindy M. Mann ${ }^{1}$, Julie L. Markham ${ }^{1}$, John E. Gustafson ${ }^{2}$, John R. Warmington ${ }^{2}$ \\ and S. Grant Wyllie ${ }^{1}$ \\ ${ }^{1}$ Centre for Biostructural and Biomolecular Research, University of Western Sydney, Hawkesbury, \\ Richmond, New South Wales, Australia. \\ ${ }^{2}$ Genetica Biotechnologies, Bentley, Western Australia. \\ *Author to whom correspondence should be addressed. E-mail: $\underline{\text { s.cox @uws.edu.au }}$ \\ Received: 17 August 2000 / Accepted: 20 October 2000 / Published: 16 January 2001
}

\begin{abstract}
Research into the mode of action of the essential oil of Melaleuca alternifolia (Tea tree oil) is briefly reviewed. Its mode of action is interpreted in terms of the membrane-toxicity of its monoterpenoid components and different approaches for determining cell membrane damage are discussed.
\end{abstract}

Keywords: essential oil, monoterpene, antimicrobial, tea tree.

\section{Introduction}

Many plant-derived essential oils are known to exhibit antimicrobial activity against a wide range of bacteria and fungi $[1,2]$. Although they usually occur as complex mixtures their activity can generally be accounted for in terms of their major monoterpenoid components. Research into the antimicrobial actions of monoterpenes suggests that they diffuse into and damage cell membrane structures $[3,4,5,6]$. Monoterpenes are lipophilic and, by definition, will preferentially partition from an aqueous phase into membrane structures. Sikkema and co-workers have shown that this causes expansion of the membrane, increased fluidity or disordering of the membrane structure and inhibition of membraneembedded enzymes [5].

The essential oil of Melaleuca alternifolia (tea tree oil) consists largely of cyclic monoterpenes of which about 50\% are oxygenated and about 50\% are hydrocarbons. It exhibits a broad-spectrum antimicrobial activity that can be principally attributed to terpinen-4-ol [7]. Here we use an 
investigation into the mode of action of tea tree oil as an example to illustrate how the membrane toxicity of monoterpenes affects microbial viability and cell membrane-related physiology.

\section{Results and Discussion}

The effects on different parameters were measured for the Gram negative (Escherichia coli AG 100) and Gram positive (Staphylococcus aureus NCTC 8325) bacteria and and a yeast (Candida albicans KEM H5) after exposure to $0.5 \% \mathrm{v} / \mathrm{v}$ tea tree oil (Figure 1). In each case measurements were taken after 60 minutes exposure, with the exception of respiration which was determined 2 minutes after tea tree oil addition in the case of E. coli and C. albicans and after 10 minutes for Staph. aureus.

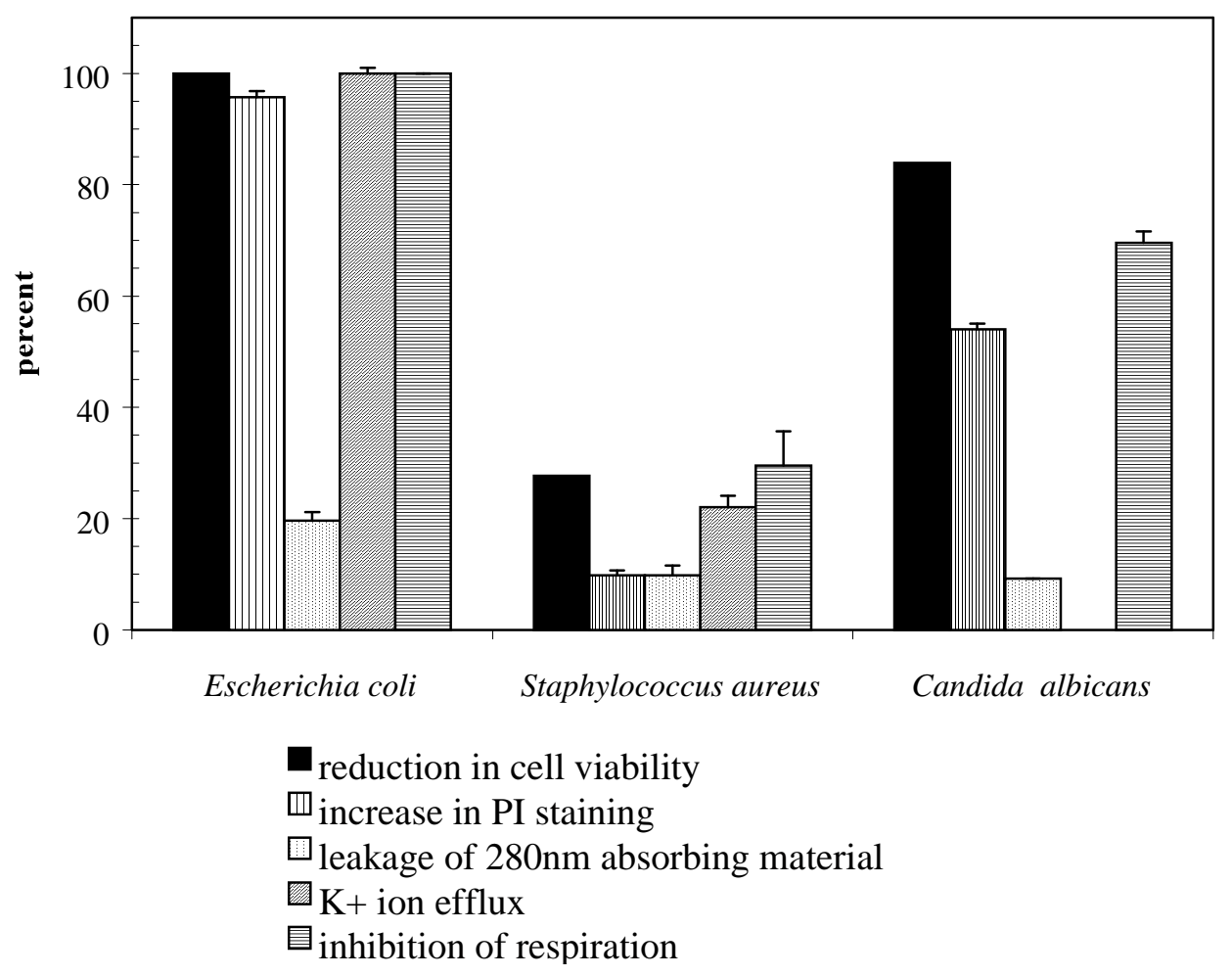

Figure 1. Effects of $0.5 \% \mathrm{v} / \mathrm{v}$ tea tree oil on various physiological indicators in microorganisms.

Cell viability counts reveal the extent to which treated cells are able to survive and reproduce to form colonies when removed from the presence of tea tree oil and re-cultured in a nutrient medium. $E$. coli and $C$. albicans cultures were more susceptible to tea tree oil than Staph. aureus during the 60 minute experiment (Figure 1). A significant inhibition of respiratory oxygen consumption in cultures of all three organisms resulted upon exposure to tea tree oil. The enzymes and cofactors directly involved in the respiratory electron transport chain span the cytoplasmic membranes of bacteria and the plasma and mitochondrial membranes of yeast. Therefore, the inhibitory effects of tea tree oil are consistent with effects related to the partitioning of its monoterpene components into cell membranes. 
Increased propidium iodide (PI) staining and leakage of $280 \mathrm{~nm}$ absorbing materials in all three microorganisms indicates that the decline in viability and the inhibition of respiration was accompanied by increased cell membrane permeability. PI is a fluorescent nucleic acid stain that is unable to penetrate the cell membrane structures of healthy cells [8]. However, cells with damaged or permeabilised cell membranes do not exclude PI. Therefore, PI staining of cells indicates cytoplasmic membrane (bacteria) and plasma membrane (yeast) damage. For E. coli the percentage of cells stained with PI after 60 minutes indicates that practically all non-viable cells had damaged cytoplasmic membranes. The fact that $100 \%$ of the total cellular free $\mathrm{K}^{+}$content (the amount released from cells treated with cell-lytic enzymes) had leaked out to the supernatant confirms this observation. The amount of $280 \mathrm{~nm}$ absorbing material in E. coli cell supernatants (relative to the total released upon complete cell lysis) was less extensive than $\mathrm{K}^{+}$ion leakage. This indicates that the membrane structural damage sustained by E. coli cells, although lethal, did not result in the release of macromolecular cytosolic constituents.

The bacterial cytoplasmic membrane provides a permeability barrier to the passage of small ions such as $\mathrm{H}^{+}, \mathrm{K}^{+}, \mathrm{Na}^{+}$and $\mathrm{Ca}^{2+}$. This impermeability to small ions is maintained and even regulated by the structural and chemical composition of the membrane itself. Increases in the leakage of $\mathrm{K}^{+}$will indicate a disruption of this permeability barrier. Maintaining ion homeostasis is integral to the maintenance of the energy status of the cell as well as membrane-coupled, energy-dependent processes such as solute transport, regulation of metabolism, control of turgor pressure and motility $[9,10,11]$. Therefore, even relatively slight changes to the structural integrity of cell membranes can detrimentally affect cell metabolism and lead to cell death.

In Staph. aureus cultures the percentage of PI permeable cells and $280 \mathrm{~nm}$ absorbing compounds released after tea tree oil exposure was similar. However, these values were significantly less than the percentage of non-viable cells. On the other hand, $\mathrm{K}^{+}$efflux and therefore, the extent of cytoplasmic membrane damage closely followed the effect on cell viability. This suggests that, in the case of Staph. aureus, monitoring $\mathrm{K}^{+}$efflux may be a more sensitive indicator of membrane damage than PI staining.

In the case of C. albicans, only 54\% of cells were permeable to PI after exposure to tea tree oil in spite of an $84 \%$ reduction in viability. This indicates that for both C. albicans and Staph. aureus PI staining does not correlate completely with the onset of cell death. In spite of the increased permeability to PI and the rapid effect on respiration $(69.6 \%$ inhibition within 2 minutes of adding tea tree oil), leakage of $\mathrm{K}^{+}$from $C$. albicans cells exposed to tea tree oil was not detected. This absence of $\mathrm{K}^{+}$efflux is difficult to explain, although it may be possible that the inhibition of respiration in some way causes the yeast plasma membrane to become permeable to the influx of PI while still maintaining a barrier to the efflux of $\mathrm{K}^{+}$. Regardless of the explanation, these findings suggest that monoterpeneinduced cell membrane damage produces different effects in different microorganisms.

\section{Conclusions}

The ability of tea tree oil to inhibit respiration and increase membrane permeability in microbial cells suggests that its lethal actions are primarily the result of inhibition of membrane-located metabolic events and a loss of chemiosmotic control. Differences in susceptibility between E. coli, 
Staph. aureus and to some degree $C$. albicans can be explained by differences in the extent of monoterpene-induced cell membrane damage. However, in the case of $C$. albicans the absence of tea tree oil stimulated $\mathrm{K}^{+}$efflux and the presence of non-viable cells with plasma membranes that remained impermeable to PI indicates that the nature of membrane damage sustained may vary from that observed with bacteria.

\section{Experimental}

The tea tree oil (Batch 6081, Main Camp, Ballina, NSW, Australia) used in this study conformed to the international standard for Oil of Melaleuca, terpinen-4-ol type [12]. Gas chromatographic analysis showed that its main components are terpinen-4-ol (39.8\%), $\gamma$-terpinene $(17.8 \%), \alpha$-terpinene $(8.3 \%)$, 1,8-cineole (4.5\%), $\alpha$-terpineol (3.4\%), $\alpha$-terpinolene (3.3\%), $p$-cymene $(2.3 \%), \alpha$-pinene $(2.1 \%)$ and limonene $(1.1 \%)$. Its sesquiterpene fraction includes aromadendrene $(1.2 \%)$, viridiflorene $(1.2 \%), \delta$ cadinene $(1.5 \%)$, globulol $(0.5 \%)$ and viridiflorol $(0.4 \%)$.

Cells were twice passaged in Iso-sensitest Broth (ISB, Oxoid, Basingstoke, UK) in the case of $E$. coli strain AG100 and Staph. aureus NCTC 8325 and Malt extract broth (MEB, Oxoid) for C. albicans KEM H5 at $37^{\circ} \mathrm{C}$. Cell viability was determined by serial dilution and plating onto nutrient agar [13].

Microbial respiration rates and potassium ion concentration in cell suspensions were measured using an oxygen electrode and a potassium ion selective electrode, respectively [6]. Propidium iodide uptake was measured by flow cytometric analysis [13]. The release of $280 \mathrm{~nm}$ absorbing compounds to cell supernatants was measured spectrophotometrically. Briefly, cells suspensions were prepared as for $\mathrm{K}^{+}$efflux determinations. Cell supernatants were obtained by centrifugation of $1 \mathrm{~mL}$ aliquots of tea tree oil exposed cells. Background leakage rates (no tea tree oil added) were negligible. The extent of leakage of $280 \mathrm{~nm}$ compounds was expressed as a percentage of values measured in supernatants from suspensions treated with cell-lytic enzymes [6].

\section{References}

1. Janssen, A.M.; Scheffer, J.J.C.; Baerheim Svendsen, A. Antimicrobial activity of essential oils. A 1976-1986 literature review. Aspects of test methods. Planta Medica, 1986, 53, 395-398.

2. Beylier, M.F. Bacteriostatic activity of some Australian essential oils. Perfumer and Flavorist, 1979, 4, 23-25.

3. Andrews, R.E.; Parks, L.W.; Spence, K.D. Some effects of Douglas fir terpenes on certain microorganisms. Appl. Environ. Microbiol. 1980, 40, 301-304.

4. Uribe, S.; Ramirez, J.; Peña, A. Effects of $\beta$-pinene on yeast membrane functions. J. Bacteriol. 1985, 161, 1195-1200.

5. Sikkema, J.; de Bont, J.A.M.; Poolman, B. Mechanisms of membrane toxicity of hydrocarbons. Microbiol. Rev. 1995, 59, 201-222.

6. Cox, S.D.; Gustafson, J.E.; Mann, C.M.; Markham, J.L.; Liew, Y.C.: Hartland, R.P.; Bell, H.C.; Warmington, J.R.; Wyllie, S.G. Tea tree oil causes $\mathrm{K}^{+}$leakage and inhibits respiration in Escherichia coli. Lett. Appl. Microbiol. 1998, 26, 355-358. 
7. Southwell, I.A.; Hayes, A.J.; Markham, J.L.; Leach, D.N. The search for optimally bioactive Australian tea tree oil. Acta Hort. 1993, 334, 265-275.

8. Mason, D.J.; Dybowski, R.; Larrick, J.W.; Gant, V.A. Antimicrobial action of rabbit leukocyte CAP18 106-137. Antimicrob. Agents Chemother. 1997, 41, 624-629.

9. Trumpower B.L.; Gennis, R.B. Energy transduction by cytochrome complexes in mitochondrial and bacterial respiration: the enzymology of coupling electron transfer reactions to transmembrane proton translocation. Annu. Rev. Biochem. 1994, 63, 675-716.

10. Booth, I.R. Regulation of cytoplasmic pH in bacteria. Microbiol. Rev. 1985, 49, 359-378.

11. Poolman, B.; Driessen, A.J.M.; Konings, W.N. Regulation of solute transport in Streptococci by external and internal pH values. Microbiol. Rev. 1987, 51, 498-508.

12. Anon. Oil of Melaleuca, terpinen-4-ol type (Tea Tree Oil). ISO 47301996 (E), 1996, International Standards Organization, Geneva.

13. Cox, S.D.; Mann, C.M.; Markham, Bell, H.C.; Gustafson, J.E.; Warmington, J.R.; Wyllie, S.G. The mode of antimicrobial action of the essential oil of Melaleuca alternifolia (tea tree oil). J. Appl. Microbiol. 2000, 88, 170-175.

Sample Availability: Samples are available from the authors.

(C) 2001 by MDPI (http://www.mdpi.org). Reproduction is permitted for noncommercial purposes. 